\title{
Imagination inflation for action events: Repeated imaginings lead to illusory recollections
}

\author{
LYN M. GOFF and HENRY L. ROEDIGER III \\ Washington University, St. Louis, Missouri
}

\begin{abstract}
In two experiments, subjects heard simple action statements (e.g., "Break the toothpick"), and, in some conditions, they also performed the action or imagined performing the action. In a second session that occurred at a later point (10 min, $24 \mathrm{~h}, 1$ week, or 2 weeks later), subjects imagined performing actions one, three, or five times. Some imagined actions represented statements heard, imagined, or performed in the first session, whereas other statements were new in the second session. During a third (test) phase, subjects were instructed to recognize statements only if they had occurred during the first session and, if recognized, to tell whether the action statement had been carried out, imagined, or merely heard. The primary finding was that increasing the number of imaginings during the second session caused subjects to remember later that they had performed an action during the first session when in fact they had not (imagination inflation). This outcome occurred both for statements that subjects had heard but not performed during the first session and for statements that had never been heard during the first session. The results are generally consistent with Johnson, Hashtroudi, and Lindsay's (1993) source monitoring framework and reveal a powerful memory illusion: Imagining performance of an action can cause its recollection as actually having been carried out.
\end{abstract}

Imagery has long been known to exert powerful effects on remembering. The ancient Greeks discovered that imagining items in particular locations was an aid to remembering them and experimental psychologists have long studied the power of imagery as an aid to remembering (e.g., Bower, 1970; Paivio, 1969, 1986). Of course, when imagery is used as a mnemonic technique, the interest is in improving recollection for facts or events that the rememberer would like to recall at some later point. However, people use imagery for many other purposesin daydreaming, in fantasies, in setting goals, in wishing for future events, and in thinking about past events. The question we ask in the present paper is whether imagining might have deleterious consequences for memory, as well as the oft-noted positive effects. Briefly, the question we ask is: If people imagine performing some action, might they later remember that they actually did it?

We review four literatures as background for our experiments. First, because our experiments are grounded in Johnson's (1988; Johnson, Hashtroudi, \& Lindsay, 1993 ) source monitoring framework, we briefly review some of its key ideas. Second, we review the evidence that

The research reported here was conducted in partial fulfillment of a master's degree at Rice University by L.M.G. under the direction of H.L.R. We appreciate the comments of Randi Martin and Michael Watkins, who served on the committee, and those of Ira Hyman and John Wixted, who read a previous version. Portions of this research were reported at the International Congress of Psychology, Montreal, August 1996 and the 37th Annual Meeting of the Psychonomic Society, Chicago, November 1996. Correspondence should be addressed to Henry L. Roediger III, Department of Psychology, Box 1125 Washington University, One Brookings Drive, St. Louis, MO 63130-4899 (e-mail: roediger@artsci.wustl.edu). imagery generally improves retention on explicit memory tests. Third, we consider prior work showing imagination inflation, or the tendency to remember events that (probably) never happened after imagining their occurrence. Fourth, we review a few key findings from the literature on memory for action events, which is the task we used in our attempt to demonstrate imagination inflation in a tractable laboratory paradigm.

\section{Source Monitoring}

Source monitoring is the ability to identify the original source of information retrieved from memory, which is often a critical aspect of remembering (Johnson et al., 1993). Source information can be used to judge the validity and importance of information retrieved from memory. If we know the source, we can give the appropriate weight to the information and take the appropriate action.

Johnson (1988) provided a useful framework for source monitoring, dividing the process into three stages. To identify a source, first a reality monitoring decision must be made: One must decide if the memory was perceptually derived (originating in the outside world) or was self-generated (thought or imagined). If the event was externally derived, then an external source decision must be made. Did the information come from person $A$ or person $\mathrm{B}$, from the newspaper or from television, or from a different external source? If the event was internally derived, then an internal source monitoring decision must be made. Internal source monitoring includes determining whether the event was actually done or if it was only thought about or imagined (did I take the pill or did I only think about taking it?). Although all stages in source monitoring are important, the experiments re- 
ported here focus on internal source monitoring judgments - those that distinguish between actions done and ones that were only imagined.

Johnson and her colleagues (e.g., Hashtroudi, Johnson, \& Chrosniak, 1990; Johnson, Foley, Suengas, \& Raye, 1988; Suengas \& Johnson, 1988) have found qualitative differences between memories based on actual perceptions and memories based on imagination. These differences presumably help us identify, most of the time, the proper source of our memories. Memories of actual events usually include more perceptual detail, contextual information, semantic detail, and emotional information than do memories of imagined events. Memories of imagined events have more information about cognitive processes, such as thinking about what color to make mental objects or mentally creating the sound of someone's voice (Johnson et al., 1993). Such cognitive processes are necessary elements of creating a mental image or contemplating possible scenarios of action. The more difficult the image is to create, the more elaborate the cognitive processes needed, and hence the better remembered they will be. The assumption is that more cognitive operations are required for imagined events than for perceived events, because perceiving an event generally takes less mental effort than does imagining or generating its occurrence.

\section{Imagery as a Memory Enhancer}

As already noted, imagery usually improves memory. Imagery instructions can be extremely powerful memory aids (Paivio, 1971). For instance, Erdelyi, Finkelstein, Herrell, Miller, and Thomas (1976) had three groups of subjects study 48 items (as words, as pictures, or as words with the instruction to imagine the corresponding pictures). Recall of the items on an initial recall trial showed the typical picture superiority effect: More pictures (26.6) were recalled than words (22.1). The most interesting condition for these purposes was the words with instructions to imagine the picture. Of these, 25.6 were recalled, revealing a significant effect of forming "mental pictures." Because imagery can have a powerful effect on memory, it is one of the main ingredients of many mnemonic techniques (see, e.g., Higbee, 1988).

Although imagery often enhances memory performance as measured by recall or recognition tests, we predicted that imagination would have deleterious consequences for the accuracy of source monitoring. Many studies have supported the idea that perception and imagination are very similar in several respects (e.g., Farah, 1985; Finke, 1980; McDermott \& Roediger, 1994). The more imagining is like perceiving, the more likely the subject will make a source monitoring error and mistakenly judge that an event was perceived when it was only imagined, and vice versa. Events that require less effort to imagine should be more confusable with real perceptions because of the similar cognitive processes.
Johnson and her colleagues (e.g., Johnson et al., 1988) have found that imagining an event once can lead to source monitoring confusions. But what is the effect of multiple imaginings on source monitoring? Some investigations have examined the effects of repeated generation or imagination on source monitoring (Johnson, Raye, Wang, \& Taylor, 1979; Kausler, Lichty, \& Freund, 1985; Kunzendorf, 1992). All of these studies measured estimated frequency of the actual event taking place as a function of the number of times the event actually took place and the number of times the event was imagined. Findings showed that imagining an event multiple times increased the estimated frequency of the actual events. However, all of these events actually did take place and subjects changed only their estimate of the number of times the events occurred. In the two experiments reported here, we asked if repeated imaginings could cause subjects to remember that they had actually done something they had only imagined doing, an effect that has been labeled imagination inflation.

\section{Imagination Inflation}

Although many variables may create memory illusions (see Roediger, 1996, for a review), imagination is a potentially potent source of false memories. Imagination has been examined experimentally as a cause of illusory memories, but there are, as yet, relatively few studies (e.g., Anderson, 1984). Recently, Garry, Manning, Loftus, and Sherman (1996) showed that imagining childhood events as an adult increases subjects' ratings of the likelihood that the event actually took place during childhood, a phenomenon they termed imagination inflation. Garry et al. gave adult subjects a questionnaire asking how likely various events (e.g., "broke a window with my hand") were to have happened to them when they were children. Subjects then were asked to create detailed images of some of the events they had previously rated as having a very low likelihood of actually occurring. Later, subjects again rated how likely the events were to have happened. Subjects were more likely to increase their ratings of likelihood for the events that were imagined than for events that were not imagined. This outcome may reflect a source monitoring error: Subjects may think the event actually happened during their childhoods when in reality they only imagined that it did. However, as Garry et al. observed, it is impossible to know what actually happened to these subjects when they were children. Therefore, in this study there is no way to determine whether imagination leads to greater true recall or to misattribution errors.

In a slightly different paradigm, Hyman, Husband, and Billings (1995) avoided this problem by writing to the parents of the subjects and asking them for events from the subjects' childhoods. In this case, the authors had to assume that the parents' memories were accurate and they did not temporarily forget any of the possible 
scenarios about which they were asked. After receiving the "true" events from the parents, the experimenters asked subjects to describe events (the true events along with one false event) from their childhoods. The subjects were given two (Experiment 1) or three (Experiment 2) tests during interviews in an effort to increase their memories for the events. About $25 \%$ of the subjects came to describe events that, according to their parents, never actually happened. Again, these subjects may have been making a source monitoring error. They could have made a mistake in calling an event imagined during the interview a true event because they were unable to properly identify its source. Hyman and Pentland (1996) also found imagination inflation using the same basic procedure as Hyman et al. In addition, during the three interviews, guided imagery was included for the events that subjects could not initially recall. Under these conditions, almost $40 \%$ of the subjects recalled details of an event that never happened, except in their imaginations. An additional interpretational difficulty with these studies is that imagination was confounded with oral discussion of the events. By focusing our subjects on imagination without speaking, we circumvented this potential problem.

The conclusion from these studies was that imagining a childhood event inflates the subject's belief that it actually happened, but these studies used events from the distant past where there can be no control over whether the events actually occurred. The present experiments examine imagination inflation in a laboratory paradigm in which the events could be brought under experimental control. The materials for these experiments were simple action events such as "break the toothpick" and "bounce the ball" that subjects could actually perform in the lab or only imagine performing. These events are usually remembered with considerable accuracy (as discussed in the next section), and of course we could know what actually happened instead of relying on subjects' initial memories (Garry et al., 1996) or parents' memories (Hyman et al., 1995) to determine the status (real or imagined) of the original event. We next review studies of memory for action events.

\section{Memory for Action Events}

Research shows that memory for action events is different in several ways from memory for items that are not physically acted out. Cohen and his colleagues (e.g., Cohen, 1981; Cohen, Peterson, \& Mantini-Atkinson, 1987; Cohen, Sandler, \& Schroeder, 1987) and Engelkamp and his colleagues (e.g., Engelkamp \& Zimmer, 1984; Zimmer \& Engelkamp, 1985) have found that items are remembered better if they are enacted by the subject than if the statement is simply heard. For example, Engelkamp and Krumnacker (1980, cited in Engelkamp \& Zimmer, 1994) gave subjects 48 action statements to remember. Subjects either acted out the statements or just listened to them. When tested, subjects recalled $63 \%$ of the statements that were enacted compared with just $42 \%$ of items only heard. This benefit is called the action superiority effect or the enactment effect.

Some action statements in prior research used physical objects that are presented to the subject (e.g., "bend the wire"), whereas other statements did not require an actual object (e.g., "blink three times"). Cohen, Peterson, and Mantini-Atkinson (1987) compared recall of object items and nonobject items in three experiments and obtained better recall of the nonobject items. This finding was significant in their Experiments 2 and 4, but not in their Experiment 1, although the trend in Experiment 1 was in the same direction. The experiments presented here also included both object and nonobject items as a variable.

\section{EXPERIMENT 1}

Does imagining an event increase the probability that it will be remembered as having actually happened? Does repeating this process of imagination also increase the effect? These are the primary questions addressed by the experiments reported here. In addition, we ask if imagining might both help and hinder overall recognition memory. Our emphasis is on the specific issue of whether imagining an action can increase recall that it was actually performed. Of course, imagining the action during a second session might also increase the probability that subjects would report that the action statement had been heard (or heard and imagined) during the first session, but these cases are of less interest than whether imagining an action can be confused with having actually performed it.

Three experimental sessions were used in Experiment 1: an initial encoding session, an imagining session, and a test session covering the events of the encoding session. During the initial encoding session, action statements were enacted, imagined, or only heard. After completing the first session, subjects returned $24 \mathrm{~h}$ later for a session of imagining action statements zero, one, three, or five times (the imagining session). Some items imagined during this imagining session had occurred in each condition in the first session and others were new. By varying the number of times items were imagined, we could determine the effect of repeated imaginings on memories as measured by recognition and source monitoring. In the final session, which occurred 2 weeks after the first session, subjects received a recognition memory test and then made source monitoring judgments on items they recognized as having previously occurred.

\section{Method}

\section{Subjects}

Forty-four Rice University undergraduates participated for partial fulfillment of course requirements. Forty-two subjects completed all three sessions. They were tested individually. Two subjects were deleted from the analyses because they fell asleep during the second session, leaving 40 usable subjects. 


\section{Design}

The experiment featured a $4 \times 4 \times 2$ within-subjects design. The independent variables were initial presentation condition of the action statement (enacted, imagined, heard only, or not presented), number of imaginings $(0,1,3$, or 5$)$ in the second session, and type of item (object, nonobject). Presentation condition, number of imaginings, and item type were crossed orthogonally. The dependent variables were recognition and source monitoring accuracy. Confidence ratings of memory for source were also collected.

\section{Materials}

Ninety-six critical items were adopted from Cohen's (1981) pool of simple actions. Forty-eight of the items involved an external object presented before the subject (e.g., "flip the coin") and 48 of the items did not require handling an object (e.g., "tug your ear lobe"). The 96 items were randomly split into four blocks, with each block containing half object items and half nonobject items. Each of these blocks was then further divided into 4 groups of 6 , for counterbalancing purposes, which ultimately produced 16 groups of six items (three object, three nonobject). These blocks of items were rotated through encoding conditions and number of imaginings across subjects so that each item served in every condition an equal number of times.

In the first session, items were presented in one of four predetermined orders that were randomly determined, within the restriction that no more than two items in each condition (enact, imagine, hear) occurred in a row. The items alternated between object and nonobject items. A sheet of addition, subtraction, and multiplication problems was given to subjects to complete after presentation of an item that was not to be done or imagined (i.e., the heard items). For the second session, four presentation forms were created so that six items from each of the three presentation conditions were imagined one, three, or five times and six new items were imagined one, three, or five times. If an item was imagined more than once, the occasions were spaced out with a lag of at least five items between presentations. Again, the imagined items alternated between object and nonobject types. Each of the four lists of imagined actions was presented to 10 subjects. The test materials (given 2 weeks later) included all 96 of the critical items along with 40 filler items. The critical items and filler items appear in the Appendix.

\section{Procedure}

Each subject participated in three sessions, which are described in turn. Each subject was tested individually for a total of approximately $3 \mathrm{~h}$ over a 2-week period. An overview of the experiment is presented in Figure 1.

Session 1: Encoding of events. The procedures were briefly explained to each subject. They were reminded of the dates and times of the other two sessions. When the questions had been answered, the experimenter continued with the encoding session.

Subjects sat facing a table, half of which was hidden from the subjects' view by a cardboard divider that also held the objects to be presented. Subjects were informed that they would hear action statements that involved simple requests. For some statements, they would be asked to do the actions, for others they would imagine the actions, and for still others they would do math problems after hearing the action statements. The math problems were given to equate the time per item and to prevent subjects from imagining or rehearsing the statement. Subjects were told to pay special attention because the experimenter would ask them questions about the actions later. The 72 items ( 24 enacted, 24 imagined, and 24 followed by math) were read aloud by the experimenter. The items were read at a 15 -sec rate that was slow enough to give the subject time to enact or to imagine each one. Subjects continued to enact or imagine the action for the entire $15 \mathrm{sec}$. The objects were brought out one at a time when they were needed and then replaced behind the cardboard screen after the action had been completed or the $15 \mathrm{sec}$ had expired. Subjects were presented with object and nonobject items in alternation so that the experimenter had time to organize and to present the objects to the subject. The objects were presented even if the subject was only to imagine the action or listen to the statement. After the 72 action statements had been presented, subjects were reminded of their next session and then dismissed. (Twenty-four action statements in the set were not presented in the initial session.)

Session 2: Imagining. Subjects returned $24 \mathrm{~h}$ later for the second session. In this session, all items presented (by having the statements read and the objects presented) were only imagined, and never actually performed. Twelve seconds were given for each item. Of the 24 items presented in each of the three conditions in Session 1, six were now imagined being done zero, one, three, or five times. In addition, for the 24 items not presented in Session 1,

\section{TIME}

\section{Day 1 Encoding Session}

- Listen to 72 action statements such as "Break the toothpick"

-24 Hear

-24 Hear + Imagine the action

- Statements were imagined

- 24 Hear + Perform the action $0,1,3$, or 5 times.

$$
\begin{aligned}
& \text { - Imagine performing } \\
& \text { action statements, } \\
& \text { both those occurring in } \\
& \text { the Encoding session } \\
& \text { and new items. }
\end{aligned}
$$

\section{Day 15 Test Session}


six were similarly imagined zero, one, three, or five times. Subjects imagined a total of 216 actions. (Note that 24 items [ 6 each from the enacted, imagined, heard, and not-presented conditions] were not imagined in Session 2-those in the zero imaginings condition.) To help ensure that subjects actually formed an image every time, they were asked to rate the vividness of each item $(1=$ not vivid, $2=$ slightly vivid, $3=$ somewhat vivid, $4=$ very vivid, 5 = extremely vivid). After $12 \mathrm{sec}$ of imaging each item, the subjects were told to rate the vividness of their image. The subjects were reminded of their third session and then dismissed.

Session 3: Testing. Two weeks later, subjects returned and were given a recognition test and a source monitoring test. All of the 96 critical items (including the 72 encoded in Session 1) plus 40 filler items were presented in a fixed random order. Subjects were given explicit instructions to answer the recognition and source monitoring questions based only on what they remembered from Session 1 . They were told that what they did during Session 2 was not important to this test.

Think back to the first day of the experiment. You will base your recognition and source monitoring judgments on the first day only. Do not base your judgments on the second day of the experiment. What you did on that day are irrelevant to this test. Focus only on the action statements from the first day.

Subjects first answered the question, "Did you hear the action?" with a "yes" or a "no." If the subject answered "no," a confidence judgment was made $(1=$ not sure, 2 = fairly sure, $3=$ definitely sure). If the subject answered "yes," he/she made a source judgment as to whether the item had been done, imagined, or listened to on the 1 st day by marking the appropriate line. The subject also made a confidence rating on each source monitoring judgment using the same scale described above. Subjects were debriefed as to the purpose of the study and given credit for their participation.

\section{Results and Discussion}

The results for the imagination inflation data are shown in Table 1, and the recognition data are presented in Table 2. To preview the findings, imagination inflation was obtained: As the number of imaginings increased, so did the proportion of did responses to statements that had not been performed during the encoding session. In addition, recognition accuracy decreased as the number of imaginings increased, to the point that with five imaginings subjects' mean discriminability was not different from chance. Object statements were recognized better than the nonobject statements, and the enactment effect (Cohen, 1981; Engelkamp \& Zimmer, 1994) was replicated for both types of items: Statements that were enacted were better recognized. In addition, recognition was enhanced by imagining the action during encoding more than in the condition in which statements were only heard. These findings are now considered in detail. All effects deemed statistically significant meet at least the .05 level of confidence.

\section{Imagination Inflation}

Table 1 presents the mean proportion of $d i d$ responses that were false alarms (and the mean confidence rating for those items) as a function of number of imaginings. As noted previously, we were primarily interested in the question of whether imaginings could become confused with actions, so the cases in which subjects said they actually had performed the action were of most interest.
Table 1

Mean Proportions of Incorrect Did Responses and Mean Confidence Ratings as a Function of Number of Interpolated Imaginings for Experiment 1

\begin{tabular}{lcccr}
\hline & \multicolumn{4}{c}{ Number of Imaginings } \\
\cline { 2 - 5 } \multicolumn{1}{c}{ Item Type } & 0 & 1 & 3 & 5 \\
\hline Not-presented items & & & & \\
$\quad$ False alarm rate & .02 & .04 & .07 & .13 \\
$\quad$ Confidence & 2.20 & 1.80 & 2.23 & 2.59 \\
Mean of imagined, heard, and not-presented items & & \\
$\quad$ False alarm rate & .02 & .05 & .08 & .10 \\
$\quad$ Confidence & 1.85 & 2.07 & 2.12 & 2.43 \\
\hline
\end{tabular}

Table 2

Mean Proportions of Items Recognized From Session 1 as a Function of Type of Item and Number of Interpolated Imaginings in Session 2 (Data From Experiment 1)

\begin{tabular}{lcccc}
\hline \multicolumn{1}{c}{ Measures of } & \multicolumn{4}{c}{ Number of Imaginings } \\
\cline { 2 - 5 } \multicolumn{1}{c}{ Recognition } & 0 & 1 & 3 & 5 \\
\hline Hit rate (HR) & Object & & & \\
False alarm rate (FAR) & .60 & .86 & .88 & .88 \\
HR - FAR & .14 & .46 & .78 & .86 \\
$d^{\prime}$ scores & .46 & .40 & .10 & .02 \\
& 1.36 & 1.21 & .35 & .07 \\
Hit rate & Nonobject & & & \\
False alarm rate & .46 & .72 & .82 & .84 \\
HR - FAR & .21 & .45 & .68 & .82 \\
$d^{\prime}$ scores & .25 & .27 & .14 & .02 \\
& .77 & .78 & .47 & .05 \\
Hit rate & Combined & & & \\
False alarm rate & .53 & .78 & .85 & .86 \\
HR - FAR & .18 & .45 & .73 & .84 \\
$d^{\prime}$ scores & .35 & .33 & .12 & .02 \\
& 1.18 & 1.01 & .40 & .02 \\
\hline
\end{tabular}

Imagination inflation was measured two different ways, both of which are presented in Table 1. First, it was measured as the proportion of items not presented during the initial encoding session but given a did source monitoring judgment as a function of the number of imaginings (see the top two rows of Table 1). This measure reflects subjects' judgments that they had actually performed an action during the first session when in fact the action statement had not even been heard during that time. Measured this way, the effect of number of imaginings on the did false alarms was reliable $[F(3,117)=8.81$, $\left.M S_{\mathrm{e}}=.01\right]$ and consisted of a significant linear trend $\left[F(1,39)=15.93, M S_{\mathrm{e}}=.02\right]$. Therefore, imagination inflation was obtained: People remembered doing actions that they had not even heard about during the first session, and as the number of imaginings increased, so did the proportion of did responses.

When imagination inflation was defined as the mean proportion of did responses to imagined, heard, and notpresented items, the same patterns were found (see the bottom two rows of Table 1). There was a significant effect of number of imaginings $\left[F(3,117)=15.58, M S_{\mathrm{e}}=\right.$ $.003]$, with a reliable linear trend $[F(1,39)=30.32$, $\left.M S_{\mathrm{e}}=.01\right]$. The same general trend occurred for items 
that were either imagined or heard, but these individual data by themselves were not statistically reliable (hence our combining data from the three types of items). For the heard items in Session 1, the proportion of did false alarms was $.02, .05, .10$, and .08 for the zero, one, three, and five imaginings; the comparable data for the imagined items from session 1 were $.02, .07, .06$, and .08 . In sum, subjects were more likely to incorrectly claim that they had done something when they had imagined doing it several times; this trend held for all three types of items (heard, imagined, and not presented in Session 1).

Mean confidence ratings are also presented in Table 1. Because different numbers of subjects and items entered into each mean confidence rating, these should be considered exploratory data and inferential statistics could not be applied. However, the trend was for higher levels of confidence with greater numbers of imaginings, especially when all false alarms were included. Therefore, increased number of imaginings enhanced both the proportion of did responses and subjects' confidence in these responses for items that had not been performed.

\section{Recognition}

A statement was scored as a hit if the action statement was read to the subject during the encoding session in any condition (enacted, imagined, heard) and the subject responded "yes" that it had been presented. (Subjects had been instructed to say "yes" if the item had been presented in any condition in Session 1 but not if it occurred only in Session 2.) Because the false alarms to critical items not presented during the encoding session increased with number of imaginings during the second session, corrections for guessing were necessary. Statistical analyses were conducted on $d^{\prime}$ scores. In addition to the $d^{\prime}$ scores, the mean proportions of hits and false alarms and the difference between the two rates are also presented in Tables 2 and 4.

A 2 (item type: object, nonobject) $\times 4$ (number of imaginings: $0,1,3,5)$ within-subjects analysis of variance (ANOVA) compared the $d^{\prime}$ scores presented in Table 2. The main effect of item type was reliable $[F(1,39)$ $\left.=5.21, M S_{\mathrm{e}}=.79\right]$, indicating more accurate recognition for object items than for nonobject items. This outcome is different from Cohen, Peterson, and MantiniAtkinson's (1987) finding of better recall of nonobject items than object items. Possible reasons for this difference in recognition and recall of these two types of items are considered in the General Discussion. The main effect of number of imaginings was also reliable $[F(3,117)$ $\left.=25.94, M S_{\mathrm{e}}=.72\right]$, as was the interaction between the two $\left[F(3,117)=3.46, M S_{\mathrm{e}}=.66\right]$. To further investigate the nature of the interaction, object and nonobject results were tested separately in additional one-factor ANOVAs. Both tests showed a significant effect of number of imaginings [object: $F(3,117)=23.82, M S_{\mathrm{e}}=.68$; nonobject: $\left.F(3,117)=4.66, M S_{\mathrm{e}}=.70\right]$. Polynomial tests of order indicated reliable linear trends, with decreasing $d^{\prime}$ scores as the number of imaginings increased for both object items $\left[F(1,39)=93.22, M S_{\mathrm{e}}=.49\right]$ and nonobject items $\left[F(1,39)=17.45, M S_{\mathrm{e}}=.69\right]$. With more imaginings of actions in Session 2, subjects became less accurate in recognizing which actions had occurred during the first session.

Since the same general pattern of results was obtained for the two item types, the results were collapsed over item type for the remaining tests, as shown in the bottom of Table 2. For the five imaginings condition, the mean $d^{\prime}$ score (.02) was not different from zero $[t(39)=.18]$, indicating that after imagining action statements five times, subjects were not significantly better than chance at recognizing what had and had not been presented to them during Session 1. Imagining events many times on the 2nd day apparently created such source monitoring difficulties that recognition for events that had occurred on the 1st day fell to chance. All other means were different from zero [the smallest was $t(39)=3.05$ ]. The mean $d^{\prime}$ scores for 0 and 1 imaginings were not significantly different from one another $[t(39)=1.18]$. All other differences between means were significant [the smallest was $t(39)=2.18]$.

Two $t$ tests showed that enacted items $\left(d^{\prime}=.98\right)$ were more accurately recognized than imagined items $[.53$, $t(39)=9.31]$, and imagined items were in turn recognized more accurately than heard items $[.23, t(39)=$ 7.29]. These findings replicated the enactment effect and the usual improvement of imagining relative to simply listening to critical items.

\section{EXPERIMENT 2}

The results of Experiment 1 showed that subjects who experienced events in a first session and then imagined events a day later came to confuse the events on a test given 2 weeks later. Is the timing of the imagining session important to imagination inflation and to the confusion effects in recognition? We asked this question in Experiment 2 by placing the imagining session (1) immediately after the original encoding, (2) 7 days after the original encoding, or (3) immediately before the test. In all cases the test occurred 2 weeks after the original encoding session, as in Experiment 1.

One generalization from source monitoring research is that the more similar two events are, the more likely they will be confused with each other (Johnson \& Raye, 1981). One aspect of similarity is temporal proximity: The closer two events are in time, the more likely elements of the two events will be confused. Therefore, the closer the imagining session occurs after the original encoding of events, the greater should be the effects of imagination inflation and recognition confusion.

On the other hand, if the imagining session is analogous to receiving misinformation, as in Loftus's (1979) misinformation paradigm, then a different prediction might be made. Loftus, Miller, and Burns (1978) found a larger misinformation effect when the misinformation was presented at the end of the retention interval (i.e., 
right before the test) than when it was presented at the beginning of the retention interval (i.e., right after the original event). This finding is referred to as the delayed misinformation effect. Therefore, by this analogy, one might expect that in the present experiment, the closer the imagining session was to the test, the greater the impact of imagining events on judgments of their actual occurrence.

In sum, Experiment 2 addressed the question as to whether temporal placement of the imagination session would affect imagination inflation and recognition confusion. Specifically, will more confusions develop when encoding and imagining occur on the same day (as suggested by the source monitoring framework), or when the imaginings immediately precede the test, 2 weeks after encoding (by analogy to the delayed misinformation effect)? Or would there be no effect?

After an encoding phase similar to that used in Experiment 1, subjects in Experiment 2 received the various lags in a between-subjects design. One third of the subjects had the imagining session immediately after the encoding session, one third had the imagining session 1 week after encoding, and the final third of subjects had the imagining session immediately before the recognition and source monitoring tests. (Recall that in Experiment 1 , the imagining session occurred 1 day after the initial encoding session.) In all cases, the tests occurred 2 weeks after the initial session.

\section{Method}

\section{Subjects}

Thirty-eight Rice University undergraduates participated for partial fulfillment of course requirements. Thirty-six returned to complete all sessions. Twelve subjects were tested individually in each of the three conditions.

\section{Design}

This experiment featured a $4 \times 4 \times 2 \times 3$ mixed factorial design with three within-subjects variables and one between-subjects variable. The within-subjects variables were initial presentation condition (enacted, imagined, heard, not presented), number of imaginings $(0,1,3,5)$, and item type (object, nonobject) - the same as Experiment 1 . The new between-subjects variable was the placement of the imagining session during the retention interval (early, middle, or late).

\section{Materials}

The materials were identical to those of Experiment 1. Three subjects in each condition received each of the four forms for counterbalancing purposes.

\section{Procedure}

Subjects in all conditions received the same encoding and test sessions as in Experiment 1. The test session in all conditions occurred 2 weeks after encoding. The difference across the three conditions was in the placement of the imagining session, described below. Subjects in the middle condition participated in three sessions, whereas subjects in the early and late conditions participated in two sessions.

After subjects in the early condition finished Session 1, they completed a computer survey for another study that took about $7 \mathrm{~min}$. Subjects were then presented with the imagining session before being dismissed. Subjects in the middle condition returned 1
Table 3

Mean Proportions of Incorrect Did Responses (Mean of Imagined, Heard, and Not-Presented Items) and Ratings as a Function of Number of Interpolated Imaginings for Experiment 2

\begin{tabular}{lcccr} 
Placement of & \multicolumn{4}{c}{ Number of Imaginings } \\
\cline { 3 - 5 } Imagining Session & 0 & 1 & 3 & 5 \\
\hline Early & & & & \\
$\quad$ False alarm rate & .01 & .04 & .05 & .11 \\
$\quad$ Confidence & .67 & 1.58 & 2.59 & 2.66 \\
$\quad$ Middle & & & & \\
$\quad$ False alarm rate & .00 & .06 & .09 & .09 \\
$\quad$ Confidence & $.33^{*}$ & 2.23 & 2.26 & 2.51 \\
$\quad$ Late & & & & \\
$\quad$ False alarm rate & .07 & .09 & .08 & .06 \\
$\quad$ Confidence & 1.92 & 2.02 & 1.92 & 2.02 \\
\hline
\end{tabular}

*Based on data from 1 subject.

Table 4

Mean Proportions of Items Recognized From Session 1 as a Function of the Placement of Session 2 and the Number of Interpolated Imaginings (Data Are From Experiment 2)

\begin{tabular}{|c|c|c|c|c|}
\hline \multirow{2}{*}{$\begin{array}{l}\text { Measures of } \\
\text { Recognition }\end{array}$} & \multicolumn{4}{|c|}{ Number of Imaginings } \\
\hline & 0 & 1 & 3 & 5 \\
\hline \multicolumn{5}{|c|}{ Early } \\
\hline Hit rate (HR) & .51 & .77 & .85 & .92 \\
\hline False alarm rate (FAR) & .08 & .33 & .76 & .89 \\
\hline HR - FAR & .43 & .44 & .09 & .03 \\
\hline$d^{\prime}$ scores & 1.44 & 1.32 & .14 & .13 \\
\hline \multicolumn{5}{|c|}{ Middle } \\
\hline Hit rate & .42 & .72 & .78 & .82 \\
\hline False alarm rate & .13 & .23 & .62 & .65 \\
\hline HR - FAR & .29 & .49 & .16 & .17 \\
\hline$d^{\prime}$ scores & 1.04 & 1.54 & .52 & .57 \\
\hline \multicolumn{5}{|c|}{ Late } \\
\hline Hit rate & .67 & .79 & .79 & .78 \\
\hline False alarm rate & .32 & .22 & .28 & .24 \\
\hline HR - FAR & .35 & .57 & .51 & .54 \\
\hline$d^{\prime}$ scores & 1.13 & 1.81 & 1.56 & 1.59 \\
\hline
\end{tabular}

week after Session 1 for Session 2 (the imagining session). Subjects in the late condition returned 2 weeks after the encoding session for Session 2, which was followed immediately by the test session.

\section{Results and Discussion}

The imagination inflation data are presented in Table 3 , and the recognition data are shown in Table 4 . To preview, imagination inflation was obtained in the early and middle conditions but not in the late condition. Recognition accuracy was highest for the late condition, in which the imagining session occurred immediately before the test. For the early and middle conditions, the pattern of decreased recognition accuracy with increased number of imaginings replicated the findings of Experiment 1 . The results for the late condition did not follow the same pattern. In all conditions, there was a positive effect of enacting and imagining the statements relative to hearing them on the recognition test. That is, recognition was most accurate when statements were enacted; imagined items were more accurately recognized than were heard items. These results will now be considered in more detail. 


\section{Imagination Inflation}

The results pertaining to imagination inflation are summarized in Table 3. Imagination inflation was defined two different ways, as in Experiment 1: either the probability of $d i d$ responses to not-presented items or the mean probability of did responses to imagined, heard, and not-presented items. Because both methods showed the same general pattern in Experiment 2 and because the second method provides more power, only that method is reported for this experiment. When imagination inflation was defined as did responses to any statement not actually done during encoding (imagined, heard, not-presented statements), the pattern was clear. The results from the early condition are presented in the top two rows of Table 3 and reveal a significant effect of number of imaginings $\left[F(3,33)=6.07, M S_{\mathrm{e}}=.004\right]$. This effect consisted of a reliable linear trend $\left[F(1,11)=9.91, M S_{\mathrm{e}}=\right.$ .01 ], confirming the prediction of increased did responses with more imaginings. The confidence ratings also generally increased with the number of imaginings, although the data were too sparse to permit application of inferential statistics.

The results from the middle condition are presented in the middle two rows of Table 3 . Again, a reliable effect of number of imaginings was obtained $[F(3,33)=5.90$, $\left.M S_{\mathrm{e}}=.004\right]$, along with a significant linear trend $[F(1,11)=$ $\left.18.32, M S_{\mathrm{e}}=.003\right]$. Mean confidence ratings also increased as the number of imaginings increased. In both the early and middle conditions, subjects were more likely to remember carrying out commands (and they were more confident in their remembrances) as a function of increased numbers of imaginings.

The results from the late condition are shown in the bottom two rows of Table 3 . There was no effect of number of imaginings on incorrect did responses. In addition, the confidence ratings did not appear to change over the conditions. Therefore, imagination inflation did not occur in the late placement condition. In summary, imagination inflation (the increase in illusory recollection of having performed an action when in fact the performance was only imagined) was replicated in the early and middle conditions of Experiment 2 and increased with the number of imaginings.

\section{Recognition}

Recognition was scored the same way as in Experiment 1 , and $d^{\prime}$ scores were again used for the analyses. A $t$ test showed that, as in Experiment 1, object items $\left(d^{\prime}=\right.$ 1.25 ) were recognized more accurately than nonobject items $\left[d^{\prime}=0.80, t(33)=5.43\right]$, but further tests showed that item type did not interact with the other variables (all $F \mathbf{S}<1$ ). The rest of the analyses tested the data collapsed over item type. A 3 (placement of imagining session: early, middle, late) $\times 4$ (number of imaginings: 0 , $1,3,5$ ) mixed factor ANOVA was conducted on the results presented in Table 4 collapsed over encoding condition. The main effect of placement of imaginings was reliable $\left[F(2,33)=9.37, M S_{\mathrm{e}}=1.67\right]$. A follow-up $t$ test showed that recognition accuracy for the early and the middle groups did not differ with $d^{\prime}$ means of .76 and $.92[t(11)=.84]$. However, the subjects in the late condition were more accurate (mean of 1.52) than those in the early condition $[t(11)=3.13]$ and those in the middle condition $[t(11)=2.47]$. The main effect of number of imaginings was reliable $\left[F(3,99)=16.30, M S_{\mathrm{e}}=\right.$ $.55]$, as was the interaction between placement of imaginings and the number of imaginings $[F(6,99)=7.64$, $\left.M S_{\mathrm{e}}=.55\right]$. Because of this interaction, the effect of number of imaginings was examined separately for each between-subjects placement condition, presented below.

The top third of Table 4 summarizes the recognition results for the early condition. The effect of number of imaginings was reliable $\left[F(3,33)=18.76, M S_{\mathrm{e}}=.33\right]$, reflecting a decrease in $d^{\prime}$ for recognition of Session 1 items with increases in the number of imaginings in Session 2. This effect was composed of a linear trend $[F(1,11)$ $\left.=44.66, M S_{\mathrm{e}}=.35\right]$, and a cubic trend $[F(1,11)=8.30$, $M S_{\mathrm{e}}=.36$ ], reflecting the decrease in accuracy as the number of imaginings increased. The cubic trend was due to the large drop in accuracy from one imagining to three imaginings. The $d^{\prime}$ scores for three and five imaginings were not different from zero [the larger $t(11)=$ .84]. After imagining action statements three or five times in Session 2, subjects could not recognize statements from the encoding session above chance levels. Additional $t$ tests revealed that $d^{\prime}$ scores did not differ between zero and one imagining $[t(11)=.52]$ or between three and five imaginings $[t(11)=.09]$. However, the difference between one and three imaginings was reliable $[t(11)=4.33]$. The overall finding of decreased recognition accuracy with greater numbers of imaginings replicated the results of Experiment 1.

For the middle condition, a one-factor (number of imaginings: $0,1,3,5$ ) within-subjects ANOVA on the results (middle third of Table 4) yielded a reliable effect of number of imaginings $\left[F(3,33)=8.55, M S_{\mathrm{e}}=.32\right]$. This effect consisted of a reliable linear trend $[F(1,11)=$ 19.44, $\left.M S_{\mathrm{e}}=.18\right]$ and a reliable cubic trend $[F(1,11)=$ $\left.7.48, M S_{\mathrm{e}}=.54\right]$. Overall accuracy decreased as number of imaginings increased. The $d^{\prime}$ scores for all conditions were different from chance, with the exception of a marginal difference for the three imagining condition $[t(11)$ $=2.20, p=.05]$. Accuracy was not different between zero and one imagining or between three and five imaginings. The one-imagining condition was reliably different from the three-imaginings condition $[t(11)=3.39]$, as was the zero-imagining condition $[t(11)=2.97]$. This pattern basically replicates that of Experiment 1 and the early condition of Experiment 2.

The bottom third of Table 4 presents the recognition data for the late condition. A one-factor ANOVA revealed that the effect of number of imaginings was not significant. All $d^{\prime}$ scores were different from chance [the smallest $t(11)=5.39$ ]. The mean $d^{\prime}$ score for one imagining was reliably higher than for the zero-imagining condition $[t(11)=2.21]$. None of the other conditions were 
significantly different from one another. Accuracy increased with one imagining but not with more imaginings. This pattern did not replicate the effect of Experiment 1 or the other two placement conditions. Accuracy increased and then remained stable, whereas in the other conditions, recognition decreased with more imaginings.

The enactment effect was obtained in all three placement conditions, replicating the findings of Experiment 1 and previous research. In the early condition, recognition was better for enacted items $\left(d^{\prime}=1.18\right)$ than for imagined items $\left[d^{\prime}=.57, t(11)=7.85\right]$, and imagined items were recognized better than heard items $\left[d^{\prime}=.33\right.$, $t(11)=3.69]$. The middle condition also showed the same pattern: Enacted items $\left(d^{\prime}=1.14\right)$ were recognized better than imagined items $\left[d^{\prime}=.74, t(11)=3.35\right]$. Imagined items were in turn recognized better than heard items $\left[d^{\prime}=.39, t(11)=2.83\right]$. And in the late condition, enacted items $\left(d^{\prime}=1.87\right)$ were recognized better than imagined items $\left[d^{\prime}=1.52, t(11)=3.99\right]$, which were in turn recognized better than heard items $\left[d^{\prime}=.80, t(11)\right.$ $=6.80]$.

\section{GENERAL DISCUSSION}

These experiments revealed three primary results. First, imagining actions led subjects to remember that they had actually performed the actions when in fact they had not. This imagination inflation occurred both for actions that had been heard or imagined during the initial session and for events that were not presented at all during the first session. In addition, the effect increased with the number of imaginings, as did subjects' confidence about their erroneous responses. Second, imagining the performance of an action several times during a second session confused subjects as to which statements had and which had not been presented during the original encoding session. Discriminability dropped to chance after five imaginings when the two sessions occurred relatively close in time (i.e., within a week of the original encoding session). The third finding of importance was that these recognition and imagination inflation results depended on when the second (imagination) session occurred in relation to the original encoding phase and the test. These patterns held when the imagination session occurred either immediately after the study session or after a 24-h or 1-week delay, but not when the imagination session occurred just prior to the test. In addition, overall recognition was higher for the late condition than the early or middle conditions of Experiment 2, showing less interference from the imagining session with greater temporal separation from the encoding session. Each of these results will be examined more thoroughly in terms of Johnson's (e.g., Johnson et al., 1993; Johnson \& Raye, 1981) source monitoring framework and Jacoby, Kelley, and Dywan's (1989) attributional view of memory. We see these sets of ideas as complementary (even overlapping) rather than competitive, but consideration of both permits us to bring out different aspects of the data.

\section{Imagination Inflation}

Garry et al. (1996) and Hyman et al. (1995) found that a single imagining of possible childhood events inflated subjects' beliefs that these events happened to them when they were children. Figure 2 presents the imagination inflation data from the present experiments measured as all incorrect did responses (for imagined, heard, and not-presented items) across both Experiment 1 and Experiment 2. In this paradigm, subjects were usually more likely to respond that they had actually performed an action (when they had not) after they had imagined doing it three or five times.

Our experiments provide a tractable laboratory paradigm for investigating imagination inflation. In prior work examining imagination inflation in producing childhood memories in young adults, the possibility exists that imagining reminded people of events that actually had occurred (see, e.g., Garry et al., 1996; Hyman et al., 1995). In our paradigm, we gained experimental control over the to-be-remembered events and showed that imagination inflation occurred when we could be certain that subjects had never performed the actions. In addition, in prior work on imagination inflation, subjects both imagined actions and verbally described them. We did not require (or permit) subjects to verbalize while forming images (instead, they rated the vividness of their imagery), so our effects cannot be attributed to verbalization.

Imagination inflation may be understood within Jacoby et al.'s (1989) misattribution framework: Imagining the action statements five times may greatly increase subjects' familiarity with the statement and its action, leading them to make a did response because they misinterpreted the strong familiarity of the statement as indicating that they had actually performed the action (perhaps because action statements were generally well remembered). By this view, instead of attributing the familiarity to having heard and imagined the statements repeatedly during the imagining session, subjects mistakenly attributed its familiarity to their having enacted the statement during encoding.

Within a source monitoring framework, imagination inflation can be explained by assuming that subjects' repeated imaginations of the events include vivid perceptual features that could cause them to later mistake the events as actually having been performed. When subjects imagined the statement for the fifth time, they may have become so adept at imagining the particular action that the resulting mental image was similar to the perceptual encoding of actually having performed the action; hence, the similarity between image and perception caused confusion between what occurred and what was only imagined. This same line of reasoning has been used to explain why good imagers make more source monitoring errors than poor imagers (Johnson et al., 1979). All subjects may be more likely to function as good imagers if they imagine the same action or event many times. According to the possibilities presented here, 


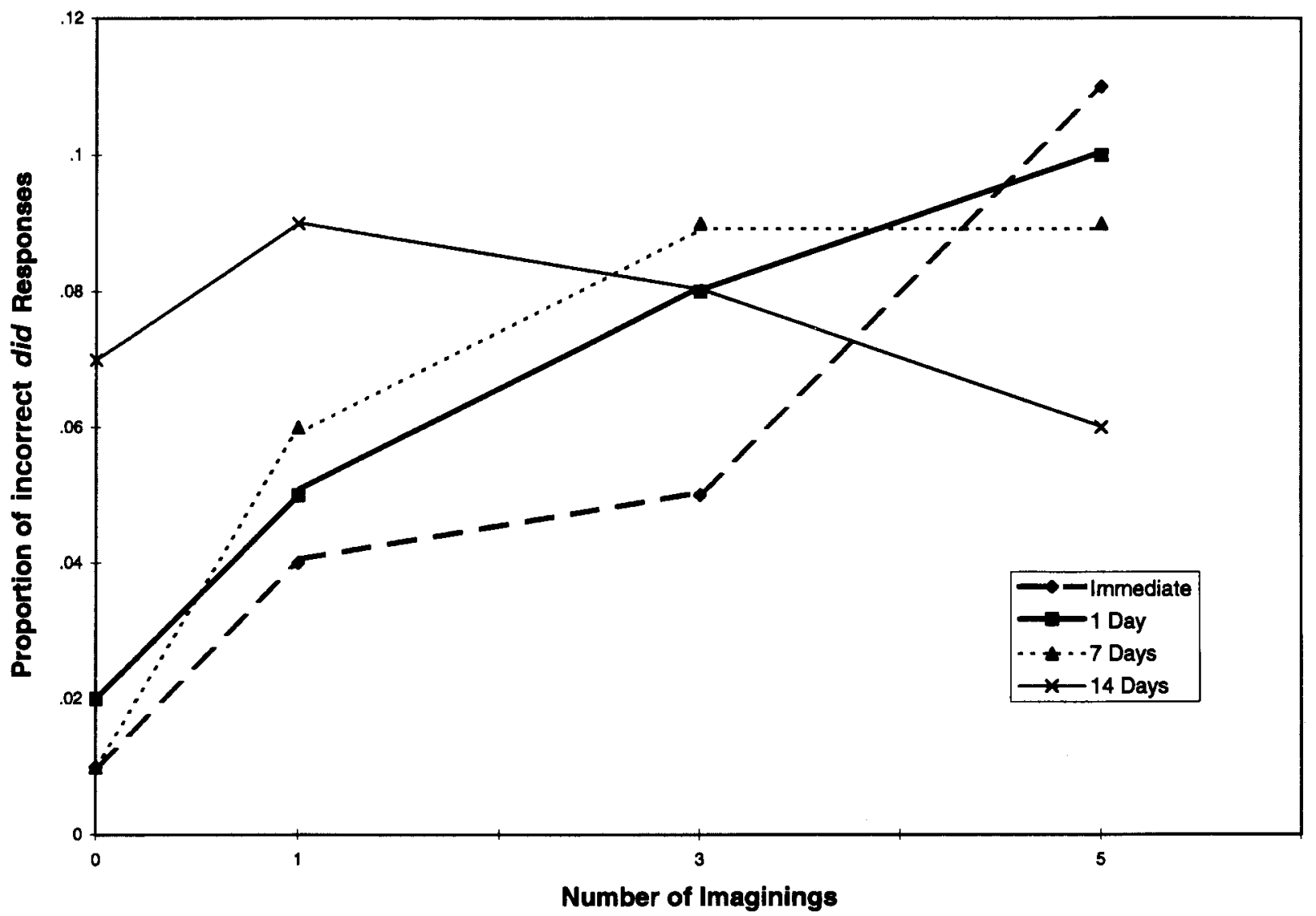

Figure 2. Imagination inflation as measured by the proportion of incorrect did responses as a function of number of imaginings and number of intervening days between Sessions 1 and 2. Immediate, earty condition of Experiment 2; 1 Day, Experiment 1; 7 Days, middle condition of Experiment 2; 14 Days, late condition of Experiment 2.

it makes sense that subjects become more confused the more times they imagine a statement either because of misattributed familiarity or because of increases in specific imaging ability.

Subjects were also more confident that they had performed the action statements if they had imagined them many times. This outcome shows that one possible scenario is wrong: As the number of imaginings increased and subjects made more errors, they might have realized that they were confused and given lower confidence ratings. This hypothetical outcome was not obtained here. The more errors the subjects made, the higher their mean confidence ratings. We expect that remember/know judgments (Tulving, 1985) would follow the same pattern, with more remember responses occurring after more imaginings, but this hypothesis must await further research.

\section{Confusions in Recognition}

In these experiments, the recognition test itself was a type of source monitoring test because of the retroactive interference supplied by the imagination session. Recall that subjects were instructed to recognize only items occurring in the initial encoding session. As was predicted, imagining had paradoxical effects on recognition. Imag- ining improved correct recognition-a positive effectbut it also greatly increased false alarms - a negative effect.

Figure 3 summarizes the recognition results (measured by hits minus false alarms, for ease of understanding) from Experiments 1 and 2 as a function of placement of the imagining session. Corrected recognition decreased with number of imaginings for both the immediate and 1-day conditions to the point that there was no difference between hit and false alarm rates after five imaginings. In the 7-day condition, corrected recognition increased with one imagining and then decreased with more imaginings. In the 14-day condition, recognition improved with one imagining and remained at that level with three and five imaginings.

Imagining may have increased hit and false alarm rates and reduced discriminability for several reasons. First, each imagining of the action statement may have acted as a rehearsal for statements presented during initial encoding and, therefore, the more the statement was imagined, the more likely it would be correctly recognized. This process would have boosted the hit rates. In addition, because imagining a statement many times increases its familiarity, subjects may later find both statements heard in the first and second sessions quite famil- 


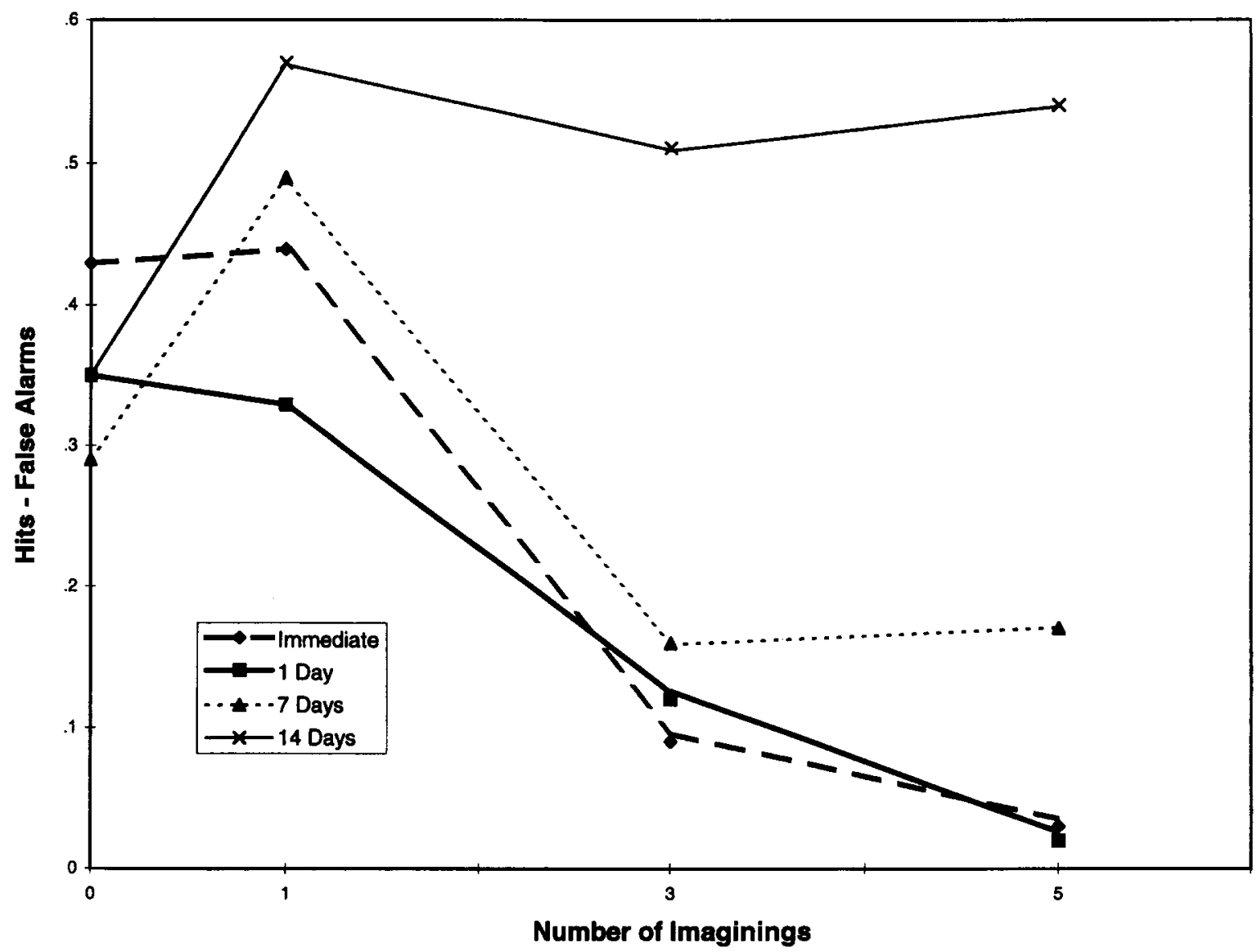

Figure 3. Recognition as measured by hits - false alarms for Experiments 1 and 2 as a function of number of imaginings and number of intervening days between Sessions 1 and 2. Immediate, earyy condition of Experiment 2; 1 Day, Experiment 1; 7 Days, middle condition of Experiment 2; 14 Days, late condition of Experiment 2.

iar, a process that would boost both hit and false alarm rates with repeated imaginings. This strong general familiarity that accrues from repeated presentations may be misattributed to occurrence during the original encoding sessions. This interpretation follows from work on familiarity and fluency by Jacoby and his colleagues (Jacoby \& Whitehouse, 1989; Kelley \& Jacoby, 1990) and by Whittlesea (1993). Familiarity is often misattributed to the incorrect source and something is called "old" that was never really presented during the relevant period of time. Such a process seemed to occur quite strongly in most conditions of the present experiments.

\section{Placement of Imagining Session}

The effect of placement of the imagining session can be readily interpreted within the source monitoring framework. Close temporal proximity of the imagining session to the encoding session (the immediate and 1day conditions) caused more confusions of what had and had not been presented during the encoding session than did delayed presentation of the imagining session (14day condition), as seen in Figure 3. The mean recognition accuracy for the middle condition fell between the two extremes. The source monitoring framework predicts that the closer two events are in time, the more likely they will be confused with each other, which is just the pattern found here. However, this finding also shows that imagining does not operate in the same manner as does postevent information in Loftus's (1979) misinformation paradigm. Loftus et al. (1978) found a delayed misinformation effect, or more errors when the misinformation was presented immediately before the test than when it was presented immediately after the original encoding. This delayed misinformation effect probably occurred because subjects had forgotten the original information and so filled in the information presented to them in the misinformation narrative.

In the late condition of Experiment 2, repeated imaginings did not produce the same dramatic effect on discriminability in the recognition test (see Figure 3), nor did they lead to imagination inflation (see Figure 2). Of course, for this late condition, there were no relevant intervening events between presentation of the imagining session and the test. Subjects may have been more accurate because of the close proximity between the imaginings and the test. If subjects were simply making a source monitoring judgment as to whether the statement was 
presented during the encoding session or only during the imagining session, then the further apart the two sessions, the easier this judgment should be. Additionally, because the imagining session and the test were on the same day, the judgment as to which day (Day 1 or Day 15) something occurred should have been much easier in this condition. This same reasoning could explain why there was no imagination inflation in the late condition. That is, imagining the statements right before the test may have reminded the subjects which activities they did during encoding and, thus, subjects would have been less likely to incorrectly claim that they had done specific actions. However, as shown in Figure 2, the proportion of incorrect did responses was no lower for the late condition than for the other placement conditions. The difference was that the proportion of did responses did not systematically change with number of imaginings.

If the temporal proximity of the two sessions (encoding and imagining) was of primary importance, one would have expected a significant difference between the early and middle conditions. This difference was not statistically significant. However, numerically, the mean $d^{\prime}$ score of the middle condition (.92) was higher than that for the early condition (.76). This may indicate that the relationship between temporal proximity and recognition performance may not be linear. This tentative finding is consistent with the temporal proximity hypothesis from the source monitoring framework.

\section{Other Findings}

Three additional findings are interesting in terms of previous research: Effect of type of item (object vs. nonobject), the enactment effect, and the effect of imagery. Each of these is discussed in turn, albeit quite briefly.

In the experiments reported here, object items were better recognized than nonobject items. Cohen, Peterson, and Mantini-Atkinson (1987) found the opposite pattern, with nonobject items remembered better than object items, but they tested their subjects using a free recall test. Since most of the nonobject items involve body parts, it is not surprising that these are recalled better. Many of the items can be generated using parts of one's own body as retrieval cues. The object items would be more difficult to retrieve from cues. However, the object items are probably more salient and thus recognized better when they are presented, as was the case here. Further work will be necessary to document differences between object and nonobject items on recognition and recall tests. The basic finding here resembles the opposite effects of word frequency on recall and recognition tests, with high-frequency words recalled better but recognized worse than low-frequency words (see, e.g., Balota $\&$ Neely, 1980). Again, further research will be required to determine whether this similarity in outcome is due to similar causes.

The enactment effect (Cohen, 1981) was replicated in all conditions of both experiments. Statements that were acted out were remembered better than statements either imagined or only heard. This is the standard finding in the literature on memory for action events as reviewed in the introduction.

Imagining usually aids memory more than when items are heard or read with no instructions to imagine; this outcome also occurred here, at least in some conditions. For items imagined only once, imagined items were better recognized than heard items in the middle and late conditions of Experiment 2 (Table 4). However, in most conditions, imagining also undermined recognition performance when subjects imagined the action more than once during the retention interval. Therefore, although imagery led to increased recognition of material that was presented in some cases, it also led to increased false recognition of items not originally presented. This type of paradox is also found in the effects of repeated testing on memory (see Roediger, McDermott, \& Goff, 1997, for a review of this evidence). Repeated testing often increases accurate memory but can also increase false memories. This same increase in accurate and inaccurate memories was found in these experiments with repeated imaginings.

\section{Applications and Future Research Directions}

These experiments replicated and extended prior research concerning the creation of false memories (e.g., Garry et al., 1996). Imagining actions created false memories about what was presented and what activity was performed on the presented statements. These results may be cautiously applied to issues surrounding eyewitness testimony and the current debate swirling around the repressed/recovered memory controversy.

Mental imagery is used in some types of interviews used by law enforcement officials to help eyewitnesses recall details of crimes. If an event that never actually happened was suggested and then imagined, could the witness later come to believe that the event did actually happen at the time of the crime? We do not know the answer to this question for certain, but the research presented here supports that possibility.

Psychologists are currently debating the existence of recovery of repressed memories (see Lindsay \& Read, 1994, for a review), with the worry being that some of these "memories" may be created by external factors rather than truly remembered. One possible cause of created memories could be imagination, as documented in the present experiments. This is especially so in therapeutic sessions in which clients are encouraged to use guided imagery to help them remember what may have happened to them long ago. Will these people come to believe that some of the imagined episodes actually happened, even when they did not? Again, the present results support this possibility, although of course the actions imagined within the context of our experiments are quite different from sexual abuse and other acts that might be recovered during therapy and contested in court. 
Nonetheless, the present studies do show that an imagined performance can later be recognized as actually having occurred.

In conclusion, imagination does not seem to act as a harmless memory enhancer, as sometimes supposed. Instead, analogous to hypnosis, imagining seems to lower a subject's threshold to call an item "remembered." Additionally, in some cases, imagining raises subjects' confidence in the false responses. Although imagination clearly has positive effects in improving memory for events that did occur, it also has the capability to confuse the imaginer as to the reality of imagined situations and events.

\section{REFERENCES}

Anderson, R. E. (1984). Did I do it or did I only imagine doing it? Journal of Experimental Psychology: General, 113, 594-613.

Balota, D. A., \& NeELy, J. H. (1980). Test-expectancy and word-frequency effects in recall and recognition. Journal of Experimental Psychology: Human Learning \& Memory, 6, 576-587.

BOWER, G. H. (1970). Imagery as a relational organizer in associative learning. Journal of Verbal Learning \& Verbal Behavior, 9, 529-533.

CoHeN, R. L. (1981). On the generality of some memory laws. Scandinavian Journal of Psychology, 22, 267-281.

Cohen, R. L., Peterson, M., \& Mantini-Atininson, T. (1987). Interevent differences in event memory: Why are some events more recallable than others? Memory \& Cognition, 15, 109-118.

Cohen, R. L., Sandler, S. P., \& Schroeder, K. (1987). Aging and memory for words and action events: Effects of item repetition and list length. Psychology \& Aging, 2, 280-285.

Engel KamP, J., \& ZimmeR, H. D. (1984). Motor programme information as a separable memory unit. Psychological Research, 46, 283 299.

Engel Kamp, J., \& Zimmer, H. D. (1994). The human memory. Seattle, WA: Hogrefe \& Huber.

Erdelyi, M. H., Finkelstein, S., Herrell, N., Miller, B., \& THOMAS, J. (1976). Coding modality vs. input modality in hypermnesia: Is a rose a rose a rose? Cognition, 4, 311-319.

FARAH, M. J. (1985). Psychophysical evidence for a shared representational medium for mental images and percepts. Journal of Experimental Psychology: General, 114, 91-103.

FINKE, R. A. (1980). Levels of equivalence in imagery and perception. Psychological Review, 87, 113-132.

Garry, M., Manning, C. G., Loftus, E. F., \& Sherman, S. J. (1996). Imagination inflation: Imagining a childhood event inflates confidence that it occurred. Psychonomic Bulletin \& Review, 3, 208-214.

Hashtroudi, S., Johnson, M. K., \& Chrosniak, L. D. (1990). Aging and qualitative characteristics of memories for perceived and imagined complex events. Psychology \& Aging, 5, 119-126.

HigBEe, K. L. (1988). Your memory: How it works and how to improve it. New York: Prentice Hall.

Hyman, I. E., Husband, T. H., \& Billuings, F. J. (1995). False memories of childhood experiences. Applied Cognitive Psychology, 9 , 181-197.

Hyman, I. E., \& Pentland, J. (1996). The role of mental imagery in the creation of false childhood memories. Journal of Memory \& Language, 35, 101-117.

JaCOBY, L. L., Kelley, C. M., \& Dywan, J. (1989). Memory attributions. In H. L. Roediger III \& F. I. M. Craik (Eds.), Varieties of memory and consciousness: Essays in honour of Endel Tulving (pp. 391 422). Hillsdale, NJ: Erlbaum.

JaCOBY, L. L., \& Whitehouse, K. (1989). An illusion of memory: False recognition influenced by unconscious perception. Journal of Experimental Psychology: General, 118, 126-135.

JOHNSON, M. K. (1988). Discriminating the origin of information. In T. F. Ottmanns \& B. A. Maher (Eds.), Delusional beliefs (pp. 34-65). New York: Wiley.
Johnson, M. K., Foley, M. A., Suengas, A. G., \& Raye, C. L. (1988). Phenomenological characteristics of memories for perceived and imagined autobiographical events. Journal of Experimental Psychology: General, 117, 371-376.

Johnson, M. K., Hashtroudi, S., \& LindSAY, D. S. (1993). Source monitoring. Psychological Bulletin, 114, 3-28.

Johnson, M. K., \& RAYE, C. L. (1981). Reality monitoring. Psychological Review, 88, 67-85.

JoHNSON, M. K., RAYE, C. L., WANG, A. Y., \& TAYLOR, T. H. (1979). Fact and fantasy: The roles of accuracy and variability in confusing imaginations with perceptual experiences. Journal of Experimental Psychology: Learning, Memory, \& Cognition, 5, 229-240.

Kausler, D. H., Lichty, W., \& Freund, J. S. (1985). Adult age differences in recognition memory and frequency judgments for planned versus performed activities. Developmental Psychology, 21, 647-654.

KeLLEY, C. M., \& JACOBY, L. L. (1990). The construction of subjective experience: Memory attributions. Mind \& Language, 5, 49-68.

KUNZENDORF, R. G. (1992). The effect of image vividness on reality monitoring. Imagination, Cognition, \& Personality, 12, 197-205.

LiNDSAY, D. S., \& READ, J. D. (1994). Psychotherapy and memories of childhood sexual abuse: A cognitive perspective. Applied Cognitive Psychology, 8, 281-338.

Lofrus, E. F. (1979). Eyewitness testimony. Cambridge, MA: Harvard University Press.

Loftus, E. F., Miller, D. G., \& Burns, H. J. (1978). Semantic integration of verbal information into a visual memory. Journal of Experimental Psychology: Learning, Memory, \& Cognition, 4, 19-31.

MCDERMOTT, K. B., \& RoEDIGER, H. L., III (1994). Effects of imagery on perceptual implicit memory tests. Journal of Experimental Psychology: Learning, Memory, \& Cognition, 20, 1379-1390.

PaIvio, A. (1969). Mental imagery in associative learning and memory. Psychological Review, 76, 241-263.

PaIvio, A. (1971). Imagery and verbal processes. New York: Holt, Rinehart \& Winston.

PaIvio, A. (1986). Mental representations: A dual coding approach. New York: Oxford University Press.

RoEDIGER, H. L., III (1996). Memory illusions. Journal of Memory \& Language, 35, 76-100.

Roediger, H. L., III, MCDermott, K. B., \& Goff, L. M. (1997). Recovery of true and false memories: Paradoxical effects of repeated testing. In M. A. Conway (Ed.), Recovered memories and false memories (pp. 118-149). Oxford: Oxford University Press.

Suengas, A. G., \& Johnson, M. K. (1988). Qualitative effects of rehearsal on memories for perceived and imagined complex events. Journal of Experimental Psychology: General, 117, 377-389.

Tulving, E. (1985). Memory and consciousness. Canadian Psychologist, 26, 1-12.

WhITTLESEA, B. W. A. (1993). Illusions of familiarity. Journal of Experimental Psychology: Learning, Memory, \& Cognition, 19, 1235 1253.

Zimmer, H. D., \& ENGElKamp, J. (1985). An attempt to distinguish between kinematic and motor memory components. Acta Psycholog. ica, 58, 81-106.

\section{APPENDIX A \\ Materials for Experiments 1 and 2}

\section{Critical Items}

Object items: sharpen the pencil, stretch the rubber band, flip the coin, put the match in the box, fold the piece of paper, unzip the zipper, bounce the ball, draw a circle on the paper, color the star, put on the ring, break the toothpick, play the drums with the pencils, open the book, shake the bottle, put the card in the envelope, put on the hat, crumple the plastic, turn the paper 90 degrees, stack the checkers, tie a knot in the string, sign your name on the paper, lift the stamp with the tweezers, pick up the chalk, put the top on the jar, flatten the clay, smell 
the flower, remove a tissue, stir the water in the cup, roll the pen on the table, slap the jack, look in the mirror, make the twist tie into a "V," ring the bell, read the time on the watch, put the marble in the cup, light the lighter, roll the dice, look through the magnifying glass, measure your middle finger with the ruler, push the toy car, put your hand in the bag, cut the cloth with the scissors, cut the cards, take the lid off the box, knock on the table, fasten the safety pin, lift the stapler, stick the pins in the cushion.

Nonobject items: cross your fingers, flex your arm, roll your eyes, point to your ankle, yawn, fake a sneeze, cross and uncross your legs, repeat 5914, rest your head in your hands, snap your fingers, shrug your shoulders, state your name, scratch your nose, clear your throat, turn around in a circle, add $2+3$, blink three times, cough twice, cup your hand over your ear, stand up and then sit down, rub your eyes, nod in agreement, look up toward the ceiling, bite your lip, tug your earlobe, salute, tap your wrist, point to your mouth, stretch your legs, count to twenty, fold your arms, count the fingers on one hand, take a very deep breath, slap your thigh, wave good-bye, touch your knees, clasp your hands together, smooth your hair in the back, touch your ear to your shoulder, raise your arms, make a tight fist, clap your hands, spell COLD, make binoculars with your hands, touch your elbow with your thumb, draw a stick man in the air, shake your head back and forth, lift your left foot.

\section{Filler Items}

close the purse, file your nails, open the knife, point to the picture, knock the walnuts together, polish the silver cup, press the button, put on the thimble, read the flash card, name the objects in the picture, button the shirt button, pat the toy dog, spin the top, open the can, shake the rattle, fold the napkin, smell the candle, tear the paper, pick up the paper clips, laugh, play the piano on the desk, tilt back in the chair, name the street you live on, name four colors, blow a kiss, blow in the air, stick out your tongue, make a sad face, lean over forward, point your toes in front, look under the table, rub your stomach, furrow your eyebrows, crack your knuckles, pinch your forearm, lick your lips, stretch up toward the ceiling, touch your cheek, touch your toes, smile.

(Manuscript received March 14, 1997; revision accepted for publication August 27, 1997.) 